\title{
MicroRNAs aid the assessment of programmed death ligand 1 expression in patients with non-small cell lung cancer
}

\author{
ANNA GRENDA $^{1}$, MARCIN NICOS ${ }^{1}$, MICHAŁ SZCZYREK ${ }^{1,2}$, PAWEŁ KRAWCZYK ${ }^{1}$, \\ TOMASZ KUCHARCZYK ${ }^{1}$, BOŻENA JAROSZ ${ }^{3}$, JULIUSZ PANKOWSKI ${ }^{4}$, MAREK SAWICKI $^{5}$, \\ JUSTYNA SZUMIŁO $^{6}$, PAULINA BUKAŁA ${ }^{1}$ and JANUSZ MILANOWSKI ${ }^{1}$ \\ Departments of ${ }^{1}$ Pneumonology, Oncology and Allergology, ${ }^{2}$ Internal Medicine in Nursing, and \\ ${ }^{3}$ Neurosurgery and Pediatric Neurosurgery, Medical University of Lublin, 20-090 Lublin; \\ ${ }^{4}$ Department of Pathology, Pulmonary Hospital, 34-500 Zakopane; Departments of \\ ${ }^{5}$ Thoracic Surgery and ${ }^{6}$ Clinical Pathology, Medical University of Lublin, 20-090 Lublin, Poland
}

Received October 12, 2018; Accepted March 7, 2019

DOI: $10.3892 / \mathrm{ol} .2019 .10207$

\begin{abstract}
The qualification of patients with non-small cell lung cancer (NSCLC) for anti-programmed cell death 1 (PD-1) or anti-programmed death ligand 1 (PD-L1) antibody therapy is based on an immunohistochemistry (IHC) assessment of PD-L1 expression. Immunological checkpoint inhibitors improve the overall survival of patients with expression of PD-L1; however certain PD-L1-negative patients may also benefit from immunotherapy. This indicates the requirement for novel predictive factors for the qualification of immunotherapy. It is also necessary to understand the mechanisms that effect the expression of PD-L1 in tumor cells. The expression of PD-L1 in 47 formalin-fixed, paraffin-embedded, NSCLC specimens was assessed using IHC and reverse transcription-quantitative polymerase chain reaction (RT-qPCR). The expression of 8 microRNAs (miRNAs, miRs) complementary to PD-L1-mRNA was also evaluated using RT-qPCR. A positive correlation was revealed between the expression level of PD-L1-mRNA and 2 miRs, miR-141 $(\mathrm{R}=0.533 ; \mathrm{P}=0.0029)$ and miR-1184 $(\mathrm{R}=0.463 ; \mathrm{P}=0.049)$. There was also a positive correlation between the percentage of PD-L1-positive tumor cells and the expression levels of miR-141 $(\mathrm{R}=0.441$; $\mathrm{P}=0.0024)$, miR-200b $(\mathrm{R}=0.372 ; \mathrm{P}=0.011)$ and $\mathrm{miR}-429$ $(\mathrm{R}=0.430 ; \mathrm{P}=0.0028)$, and between the percentage of the tumor area with immune cell infiltration and the expression levels of miR-141 $(\mathrm{R}=0.333 ; \mathrm{P}=0.03)$ and miR-200b $(\mathrm{R}=0.312 ; \mathrm{P}=0.046)$. Additionally, the percentage of tumor cells expressing PD-L1 positively correlated with miR-141 expression $(\mathrm{R}=0.407 ; \mathrm{P}=0.0055)$. Correlations between the
\end{abstract}

Correspondence to: Dr Anna Grenda, Department of Pneumonology, Oncology and Allergology, Medical University of Lublin, Jaczewskiego 8, 20-090 Lublin, Poland

E-mail: an.grenda@gmail.com

Key words: programmed death ligand 1, microRNA, non-small cell lung cancer, immunotherapy expression of the investigated miRs (particularly miR-141) and PD-L1 indicated that miRs may regulate PD-L1 expression at a post-transcriptional level.

\section{Introduction}

Programmed death ligand 1 (PD-L1) is a protein expressed by activated antigen-presenting cells, the majority of normal body cells and certain types of cancer cells. PD-L1 is an immune checkpoint protein that protects against autoimmunity (1). Certain types of cancer, including non-small cell lung cancer (NSCLC), are able to express this molecule on the cell surface. Interactions between tumor PD-L1 and programmed cell death protein 1 (PD-1) localized to the T-cell surface, cause lymphocyte anergy and the resistance of cancer cells to immune surveillance $(1,2)$. Inhibition of this signaling pathway using anti-PD-1 or anti-PD-L1 monoclonal antibodies results in mobilization of the immune system, and the subsequent recognition and destruction of cancer cells (3-7).

The effectiveness of anti-PD-1 (nivolumab and pembrolizumab) and anti-PD-L1 (atezolizumab and durmvalumab) antibody therapy in patients with NSCLC depends on the expression of PD-L1 on tumor and immune cells, which is detected using immunohistochemistry (IHC) (8-12). Immunotherapy, based on the inhibition of immune checkpoints improved overall survival in patients expressing PD-L1, but certain NSCLC patients without expression may also benefit from immunotherapy $(13,14)$. There are 2 platforms to assess PD-L1 expression in tumor cells and/or in tumor-infiltrating immune cells (9). During clinical trials with pembrolizumab and nivolumab (which bind the extracellular domain of PD-L1) the antibodies 22C3 and 28-8 were used with the Autostainer Link platform to determine the PD-L1 status of participants. Inclusion criteria for pembrolizumab therapy were $>50 \%$ of tumor cells with PD-L1 expression for first line treatment, and any expression of PD-L1 (PD-L1-positive tumor cells $\geq 1 \%$ ) for second line treatment (11). However, nivolumab may be used for second line therapy in patients without PD-L1-positive tumor cells, and testing of PD-L1 expression with the 28-8 antibody is not required to qualify patients for nivolumab therapy (9). 
The SP142 antibody, used with the Benchmark platform, was employed in clinical trials for atezolizumab. This clone can bind to the intracellular domain of PD-L1 (15). The scoring of PD-L1 status is complicated, due to the requirement of assessing expression on stromal immune cells that have infiltrated the tumor. However, atezolizumab may also be used as a second line of treatment in patients without PD-L1-expressing tumor or immune cells. The antibody clone SP263, used with the Benchmark platform, has the ability to bind the intracellular domain of PD-L1; this was examined in clinical trials with durmvalumab (13).

Differentkinds of antibodies used in the assessment of PD-L1 give incompatible scores. This may be due to the properties of particular clones and their affinity for different PD-L1 domains. There is a requirement to supplement the diagnosis of PD-L1 with additional factors, facilitating the qualification of patients for immunotherapy. Genetic factors that influence the effectiveness of this method may be identified. One such factor may be the tumor mutation burden (TMB). There are no studies using epigenetic factors as predictors for immunotherapy. However, microRNAs (miRs) present as potential candidates. miRs are small molecules ( $20 \mathrm{nt}$ in length) that regulate gene expression on a post-transcriptional level. These molecules act by either promoting mRNA degradation or inhibiting translation $(15,16)$. There are few reports concerning the regulation of PD-L1 expression by miRs in lung cancer (17-19). Therefore, the purpose of the present study was to assess the expression of miRs with the ability to regulate PD-L1 expression in patients with NSCLC, and to determine the association between these factors and the expression of PD-L1 mRNA and protein in tumor cells.

\section{Materials and methods}

Patients. A total of 43 formalin-fixed paraffin-embedded (FFPE; 91.49\%) tissues from patients with NSCLC, and 4 cell blocks $(8.51 \%)$ were assessed for the expression of PD-L1 protein, mRNA and miR. Adenocarcinoma was diagnosed in 31 (65.9\%) cases and squamous cell carcinoma was detected in 13 (27.7\%). In $3(6.4 \%)$ cases, NSCLC not otherwise specified (NOS) was diagnosed. There were $36(76.60 \%)$ specimens from primary tumors, 5 (10.64\%) from distant metastases and 6 (12.76\%) from metastases to the lymph node. Samples were collected between September 2017 and April 2018 in the Departments of Pneumonology, Oncology and Allergology, Medical University of Lublin (Lublin, Poland). The study group included 33 (70.21\%) patients at stage I-IIIA, $8(17.02 \%)$ at stage IIIB, and $6(12.77 \%)$ at stage IV. The median age was 65 years $( \pm 9.03$ years), and the group consisted of 20 male $(42.55 \%)$ and 27 female patients (57.45\%), of which 10 were non-smokers (21.28\%). Due to the lack of reimbursement for anti-PD-1 or anti-PD-L1 antibodies in Poland at the time, information regarding the efficacy of immunotherapy was not available. Therefore patients were not treated with anti-PD-1 or anti-PD-L1 monoclonal antibodies. Furthermore, surgically resected patients were enrolled, and immunotherapy in such patients was not available at the time (with the exception of those in clinical trials).

IHC analysis. During IHC analysis, the monoclonal antibody clones SP142 (Ventana Medical Systems, Inc., Tucson, AZ,
USA) and 22C3 (Dako; Agilent Technologies, Inc., Santa Clara, CA, USA) were employed. Briefly, 3- $\mu \mathrm{m}$ paraffinized tissue sections were mounted using SuperFrost ${ }^{\mathrm{TM}}$ Plus slides (Thermo Fisher Scientific, Inc., Waltham, MA, USA) on a hot-plate in $60^{\circ} \mathrm{C}$ for at least one hour. Deparaffinization and antigen retrieval were performed prior to staining, using the Dako PT Link device (Dako; Agilent Technologies, Inc.). Slides were washed and dehydrated twice in $96 \%$ ethanol and xylene, and mounted on coverslips. The slides were pre-heated to $59^{\circ} \mathrm{C}$ for at least $3 \mathrm{~h}$, and IHC with the SP142 antibody was conducted using the Ventana Benchmark GX platform (Roche Diagnostics $\mathrm{GmbH}$, Mannheim, Germany), with the Ventana test certified for in vitro diagnostics (CE-IVD). The OptiView Amplification kit was incorporated for signal amplification, and the OptiView DAB IHC Detection kit was used (Roche Diagnostics). As the negative control, a rabbit monoclonal antibody (standard negative control by Ventana Medical Systems, Inc., Tucson, AZ, USA; cat. no. 790-4795) was applied. IHC conducted with the $22 \mathrm{C} 3$ antibody was performed using the Dako Autostainer Link 48 instrument (Dako; Agilent Technologies, Inc.) incorporating the CE-IVD IHC 22C3 PharmDx PD-L1 Kit and the EnVision FLEX visualization system (Agilent Technologies, Inc.). The aforementioned staining procedures were conducted according to the manufacturer's protocols. Counterstaining with hematoxylin was also conducted according to the manufacturer's protocol. The slides were later observed by the pathologist using an Olympus BX41 microscope.

$R N A$ isolation. Total RNA isolation was conducted using $5-\mu \mathrm{m}$ sections of FFPE tissues or cell blocks using an miRNeasy FFPE Kit (Qiagen GmbH, Hilden, Germany), according to the manufacturers' instructions. RNA was stored at $-80^{\circ} \mathrm{C}$ until the synthesis of cDNA.

Quantification of PD-L1 mRNA expression level. The relative level of PD-L1 mRNA expression was determined using reverse transcription-quantitative polymerase chain reaction (RT-qPCR) in reference to the internal control, GAPDH. Reverse transcription was conducted using a High-Capacity RNA-to-cDNA ${ }^{\mathrm{TM}}$ kit (Thermo Fisher Scientific, Inc.) according to the manufacturer's instruction. qPCR was performed using TaqMan Fast Advanced Master Mix (Thermo Fisher Scientific, Inc.) and the Illumina Eco Real-Time PCR System (Illumina Inc, San Diego, CA, USA). The $20 \mu \mathrm{l}$ PCR mixture contained the following: $10 \mu \mathrm{l}$ TaqMan Fast Advanced Master Mix, $1 \mu \mathrm{l}$ TaqMan Gene Expression Assay mix (assay ID Hs00204257 for PD-L1 and Hs02786624 for GAPDH; Thermo Fisher Scientific, Inc.), $5 \mu \mathrm{l}$ RNase free water and $4 \mu \mathrm{l}$ cDNA. The thermocycling conditions were as follows: $95^{\circ} \mathrm{C}$ for $20 \mathrm{sec}$, 40 cycles at $95^{\circ} \mathrm{C}$ for $3 \mathrm{sec}$, and $60^{\circ} \mathrm{C}$ for $30 \mathrm{sec}$. Analysis was performed using the $2^{-\Delta \Delta C q}$ method (20).

Quantification of miR expression. Expression of $8 \mathrm{miRs}$, complementary to the $3^{\prime}$ untranslated region (UTR) of PD-L1 mRNA was assessed: miR-141-3p (478501_mir,), miR-200a-3p (478490_mir), miR-200b-3p (477963_mir), miR-200c-3p (478351_mir), miR-429 (477849_mir), miR-508-3p (478961_ mir), miR-1184 (478629_mir) and miR-1255a (478661_mir) were all acquired from Thermo Fisher Scientific, Inc. The targets for miRs in 3'UTR PD-L1 mRNA were predicted using 

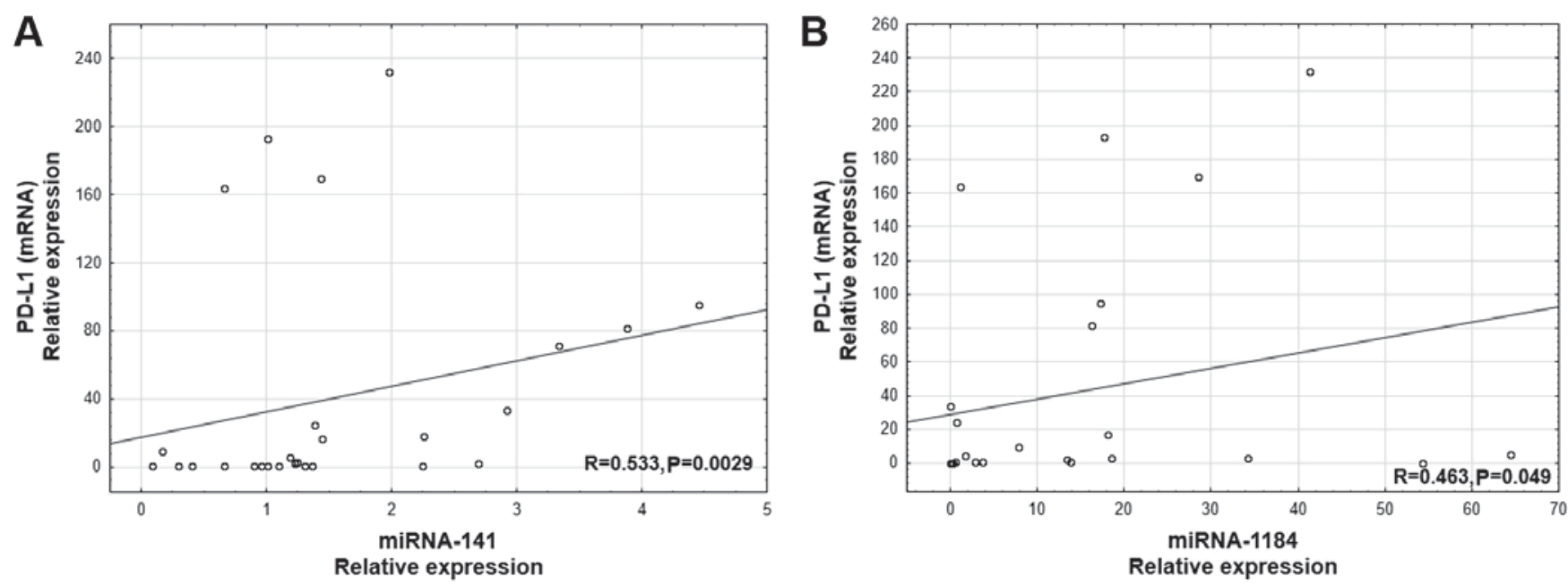

Figure 1. Correlation between (A) PD-L1 mRNA and miR-141 expression levels, and (B) PD-L1 mRNA and miR-1184 expression. PD-L1, programmed death ligand $1 ; \mathrm{miR}$, microRNA.

the TargetScan (version 7.1; www.targetscan.org) and miRBase (release no. 22; www.mirbase.org) systems. miR-191-5p (477952_mir) was used as an internal control. Reverse transcription was conducted using the TaqMan Advanced miRNA cDNA Synthesis kit (Thermo Fisher Scientific, Inc.) according to the manufacturer's instructions. qPCR was performed using the Illumina Eco Real-Time PCR System (Illumina, Inc.). The 20- $\mu$ 1 PCR mixture contained the following: $10 \mu 1$ TaqMan Fast Advanced Master Mix, $1 \mu$ l TaqMan Fast Advanced miRNA Assay mix, $4 \mu 1$ RNase free water and $5 \mu 1 \mathrm{cDNA}$. The reactions were conducted as follows: $95^{\circ} \mathrm{C}$ for $20 \mathrm{sec}, 40$ cycles at $95^{\circ} \mathrm{C}$ for $5 \mathrm{sec}$ and $60^{\circ} \mathrm{C}$ for $30 \mathrm{sec}$. Analysis was performed using the $2^{-\Delta \Delta \mathrm{Cq}}$ method (20).

Statistical analysis. Statistical analysis was performed using Statistica software (version 13.1; TIBCO $^{\circledR}$ Software Inc., Palo Alto, CA, USA). The Spearman's rank test was used to examine the correlation between the expression of miRs and PD-L1 mRNA and protein expression. The Mann-Whitney U test was used to compare PD-L1 and miR expression in different patient groups (stratified by age, material for analysis, histopathological diagnosis, and PD-L1 expression on tumor and immune cells). Data are presented as the median \pm standard deviation. $\mathrm{P}<0.05$ was considered to indicate a statistically significant difference.

\section{Results}

The median percentage of PD-L1-postive tumor cells assessed using the $22 \mathrm{C} 3$ antibody was greater than that gained using the SP142 clone $(35.00 \pm 39.95$ vs. $2.5 \pm 37.96 \%)$. The median percentage of PD-L1-positive areas of the tumor infiltrated with immune cells, as tested with SP142, was $5 \pm 22.27 \%$. Due to the degradation of mRNA, only 33 cases were assessed for PD-L1 mRNA expression. A positive correlation was observed between the expression of PD-L1 mRNA and the percentage of tumor cells with $\mathrm{PD}-\mathrm{L} 1$ expression $(\mathrm{R}=0.35 ; \mathrm{P}=0.046$ tested using 22C3, and $\mathrm{R}=0.419 ; \mathrm{P}=0.015$ using $\mathrm{SP} 142)$, and the percentage of the tumor area infiltrated by immune cells with PD-L1 expression $(\mathrm{R}=0.44 ; \mathrm{P}=0.013)$.
A positive correlation was revealed between PD-L1 mRNA level and the expression of two miRs: miR-141 $(\mathrm{R}=0.533$; $\mathrm{P}=0.0029$; Fig. $1 \mathrm{~A})$ and $\mathrm{miR}-1184(\mathrm{R}=0.463$, $\mathrm{P}=0.049$, Fig. 1B). Additionally, a positive correlation was observed between the percentage of PD-L1-positive tumor cells (IHC using SP142) and the expression of three miRs: miR-141 ( $\mathrm{R}=0.441 ; \mathrm{P}=0.0024$; Fig. 2A), miR-200b ( $\mathrm{R}=0.372$; $\mathrm{P}=0.011$; Fig. 2B), and miR-429 ( $\mathrm{R}=0.430 ; \mathrm{P}=0.0028$; Fig. $2 \mathrm{C})$. Furthermore, there was a positive correlation between the percentage of the tumor area with immune cell infiltration and the expression of two miRs: miR-141 $(\mathrm{R}=0.333 ; \mathrm{P}=0.03$; Fig. 2D) and miR-200b ( $R=0.312$; $P=0.046$; Fig. 2E). The percentage of PD-L1-positive tumor cells assessed using the 22C3 antibody positively correlated with miR-141 expression ( $\mathrm{R}=0.407$; $\mathrm{P}=0,0055$; Fig. 2F).

Patients were stratified according to PD-L1 expression. Tumor cell (TC)1/2/3 or immune cell (IC) $1 / 2 / 3$ was defined as PD-L1 expression on $\geq 1 \%$ of tumor cells, or $1 \%$ of the area of tumor infiltrated by immune cells; TC $2 / 3$ or IC $2 / 3$ were defined as PD-L1 expression on $5 \%$ of the tumor cells or the tumor area; TC3 or IC3 were defined as PD-L1 expression on $10 \%$ of these cells or the tumor area; and TC4 was defined as PD-L1 expression on $\geq 50 \%$ of all tumor cells. TC0 was used to define PD-L1-negative samples.

Groups of patients that differed by their expression levels of PD-L1 (determined by IHC using SP142) were analyzed. The expression level of PD-L1 mRNA was significantly higher in the TC4 group compared with the TC0/1/2/3 group $(\mathrm{P}=0.0055$; Fig. 3). It was also observed that the expression levels of miR-200b and miR-429 were significantly higher in the TC1/2/3 group with any PD-L1 protein, compared with the PD-L1-negative group, TC0 $(\mathrm{P}=0.043 ; \mathrm{P}=0.0088$ respectively; Fig. 4A and E). The expression levels of miR-200b and miR-141 were significantly higher in the TC2/3 group compared with the $\mathrm{TC} 0 / 1$ group $(\mathrm{P}=0.025 ; \mathrm{P}=0.012$ respectively; Fig. 4B and C). Furthermore, the expression level of miR-429 was also significantly higher in the TC3 group compared with the TC0/1/2 group ( $\mathrm{P}=0.015$; Fig. $4 \mathrm{~F})$. There were no differences in the expression of miRs in the groups that differed in the expression of PD-L1 on immune cells. 
A

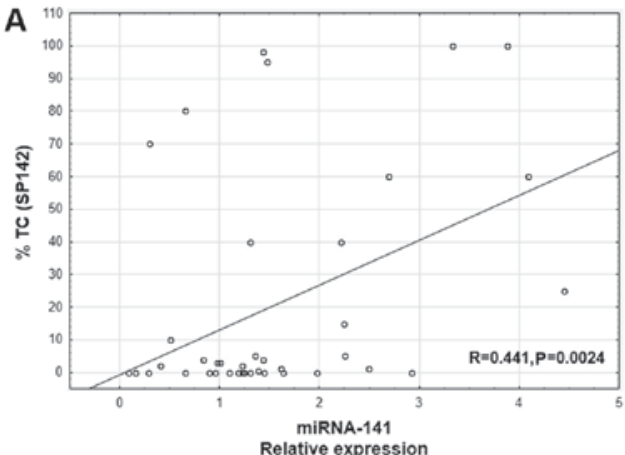

C
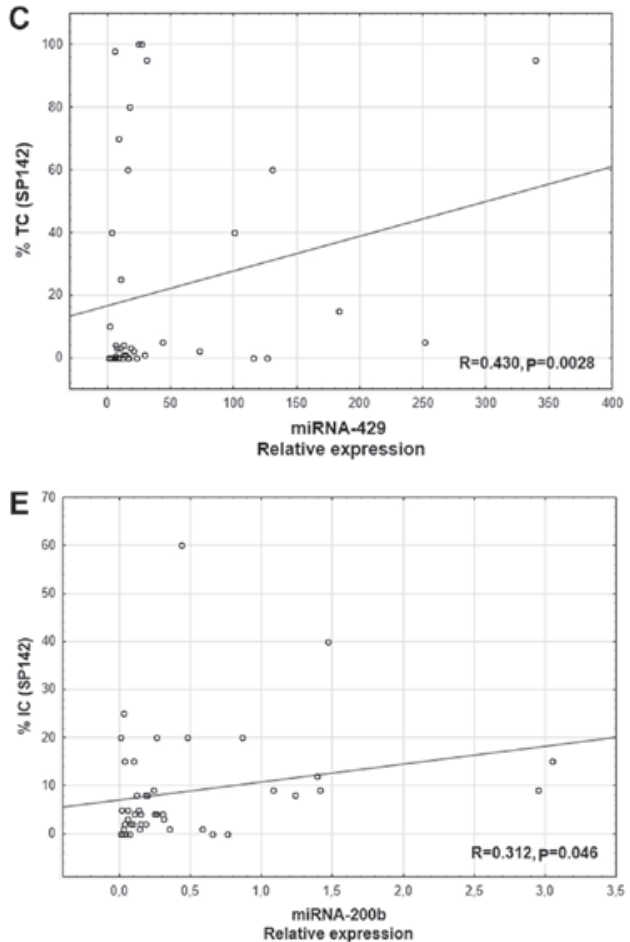

B

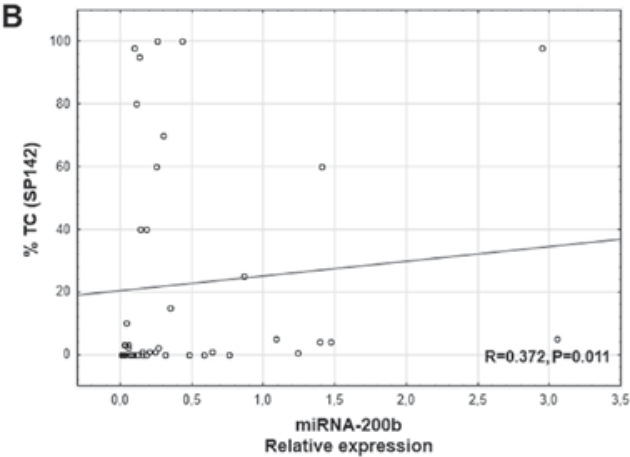

D

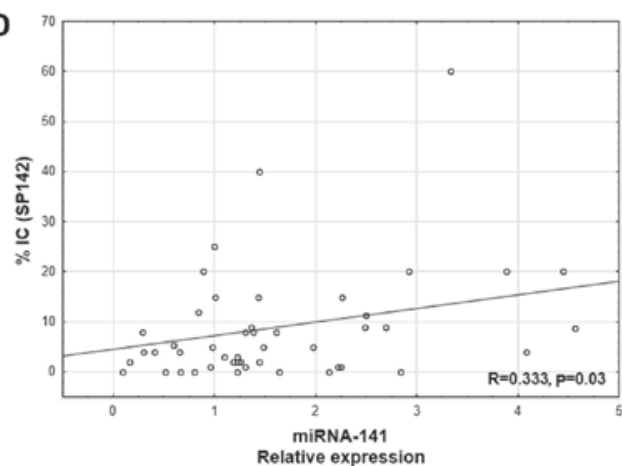

$\mathbf{F}$

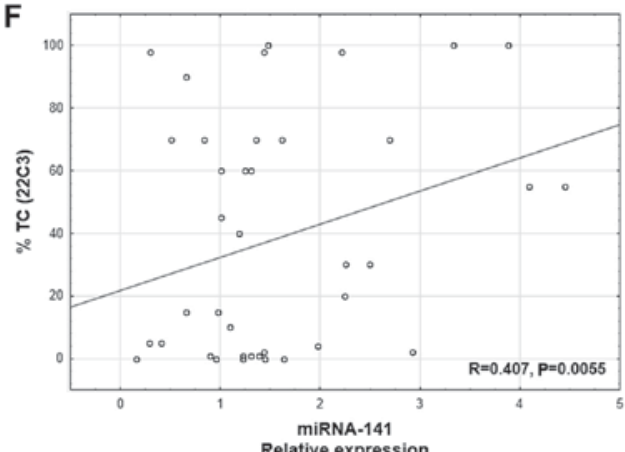

Figure 2. Correlation between the percentage of PD-L1-positive tumor cells in IHC using the SP142 antibody, and miR-141, miR-200b and miR-429 expression. (A) miR-141, n=43; (B) miR-200b, n=42; (C) miR-429, n=41. Correlation between the percentages of the tumor area infiltrated with PD-L1-positive immune cells in IHC using the SP142 antibody, and miR-141 and miR-200b expression. (D) miR-141, n=40; (E) miR-200b, n=40. (F) Correlation between the percentage of PD-L1-positive tumor cells in IHC using the 22C3 antibody, and miR-141 expression; n=39. PD-L1, programmed death ligand 1; miR/miRNA, microRNA; TC, tumor cells; IC, immune cells; IHC, immunohistochemistry.

Only one association was revealed between the expression of miR and PD-L1 on tumor cells analyzed using the 22C3 antibody; miR-141 expression was significantly higher in the TC4 group compared with in the TC $0 / 1 / 2 / 3$ group $(\mathrm{P}=0.009$; Fig. 4D). Examples of stained NSCLC tissues visualized using the SP142 or 22C3 antibodies are displayed in Fig. 5. The expression of miRs was similar in groups of patients stratified by age, sex, pathomorphological diagnosis, status of metastasis or disease stage $(\mathrm{P}<0.05)$.

\section{Discussion}

Immune checkpoint inhibitors are able to prolong patient survival, and their use has been associated with fewer side effects comparison to the chemotherapy (21). These side effects are also differently classified (Immune-Related Adverse Events) (22). The greatest benefit of PD-1/PD-L1 inhibitors was observed among patients whose tumor cells expressed

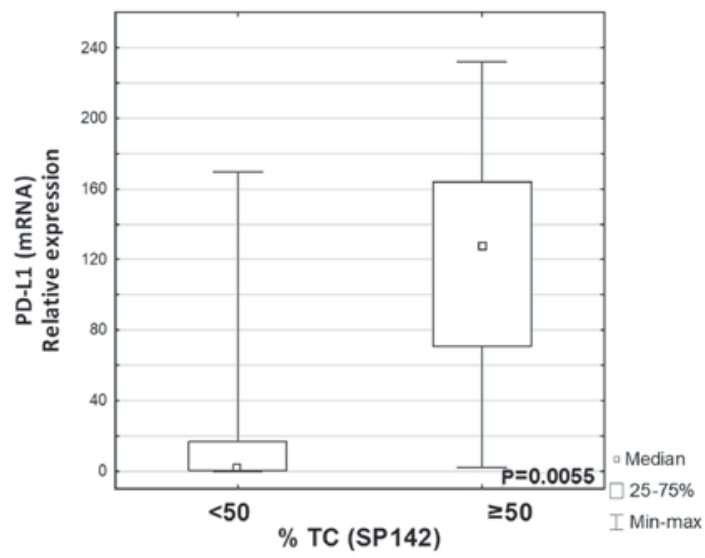

Figure 3. Differences in the expression of PD-L1 on mRNA level depending on the PD-L1 protein expression status of tumor cells in patients with non-small cell lung cancer. Higher relative expression of PD-L1 mRNA in the group with $\geq 50 \%(n=8)$ compared with the group with $<50 \%(n=25)$ of tumor positive cells (TC, SP142). PD-L1, programmed death ligand 1; miR/ miRNA, microRNA; TC, tumor cells. 

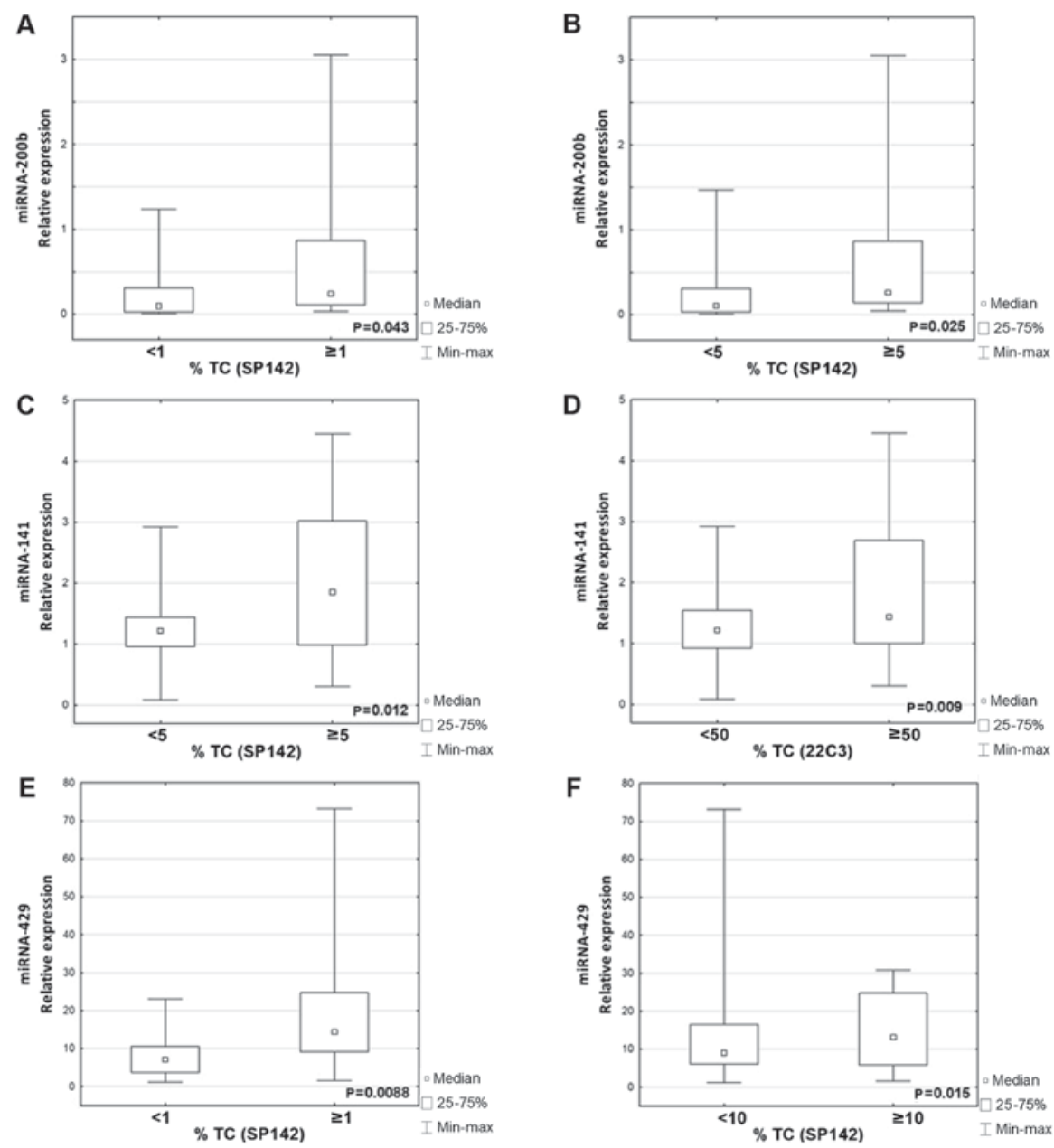

Figure 4. Differences in the expression of miRs depending on PD-L1 expression status in the tumor cells of patients with non-small cell lung cancer. (A) Higher relative expression of miR-200b in the group with $\geq 1 \%(n=24)$ compared with the group with $<1 \%(n=18)$ tumor positive cells (TC, SP142). (B) Higher relative expression of miR-200b in the group with $\geq 5 \%(\mathrm{n}=14)$ compared with the group with $<5 \%(\mathrm{n}=28)$ tumor positive cells (TC, SP142). (C) Higher relative expression of miR-141 in the group with $\geq 5 \%(n=15)$ compared with the group with $<5 \%(n=28)$ tumor positive cells (TC, SP142). (D) Higher relative expression of miR-141 in the group with $\geq 50 \%(\mathrm{n}=18)$ compared with the group with $<50 \%(\mathrm{n}=21)$ tumor positive cells (TC, 22C3). (E) Higher relative expression of miR-429 in the group with $\geq 1 \%(\mathrm{n}=21)$ compared with the group with $<1 \%(\mathrm{n}=20)$ tumor positive cells (SP142). (F) Higher relative expression of miR-429 in the group with $\geq 10 \%(\mathrm{n}=14)$ compared with that with $<10 \%(\mathrm{n}=27)$ tumor positive cells (SP142). PD-L1, programmed death ligand 1; miR/miRNA, microRNA; TC, tumor cells.
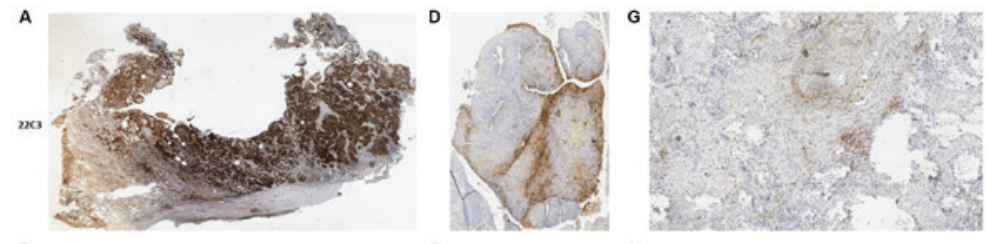

B
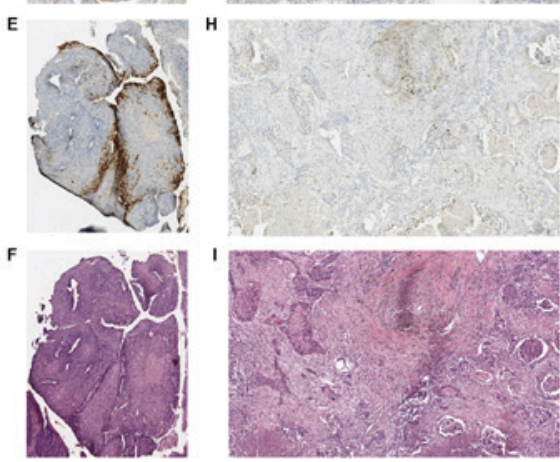

Figure 5. Example of immunohistochemistry for PD-L1 expression in non-small cell lung cancer formalin-fixed, paraffin-embedded tissues. 100\% of tumor cells exhibit PD-L1 expression of (magnification, x20), using (A) 22C3 and (B) SP142 antibodies. (D) 20\% of tumor cells exhibit expression of PD-L1 (22C3), and (E) 15\% of tumor cells exhibit expression of PD-L1 (SP142) (magnification x90). (G) 2\% of tumor cells with expression of PD-L1 (22C3). (H) 4\% of tumor cells with expression of PD-L1 (SP142) (magnification x110). (C, F and I) Hematoxylin and eosin staining (magnification, x20, x90 and x110, respectively). 
PD-L1 (9-11). Pembrolizumab and chemotherapy as first line treatments for patients with advanced NSCLC with PD-L1 expression on $>50 \%$ of tumor cells (scored using the $22 \mathrm{C} 3$ antibody) were compared. This revealed a significantly higher response rate and longer progression-free and overall survival rates in patients treated with pembrolizumab, compared with those who received platinum-based chemotherapy (6). However, the association between the benefits of second line immunotherapy and the expression of PD-L1 on tumor cells is not so obvious. Brahmer et al (10) demonstrated that overall survival, response rate and progression-free survival were significantly greater when using nivolumab, compared with docetaxel, in patients with squamous-cell cancer, regardless of tumor cell PD-L1 expression. Similarly, Rittmeyer et al (23) revealed that atezolizumab treatment resulted in a clinically relevant improvement in overall survival, compared with docetaxel in previously treated patients with NSCLC, regardless of PD-L1 expression. Patients without PD-L1 expression on tumor cells or immune cells infiltrating the tumor achieved a median overall survival of 12.6 months, following treatment with atezolizumab, and only 8.9 months following docetaxel treatment. The authors indicated that the lack of an association between PD-L1 expression and immunotherapy efficacy was probably due to the complex interactions between tumors and the immune system. There are a number of studies that suggest genetic factors may also be associated with the response to immunotherapeutic treatment, in spite of PD-L1-negative tumor cell status $(10,24,25)$.

Shukuya et al (26) indicated that miR may influence the efficiency of immunotherapy. Next-generation sequencing was used to determine the expression of specific miRs in the plasma, and the miR content of extracellular vesicles (EVs). A total of 26 circulating miRs and four EV-associated miRs exhibited significant differences in concentration between responders and non-responders to immunotherapy with anti-PD-1 or anti-PD-L1 antibodies. Furthermore, these miRs were potential predictive biomarkers for the response to treatment.

In the present study, 8 miRs with the ability to regulate the expression of PD-L1 transcripts in tumor cells were analyzed. A positive correlation between PD-L1 mRNA and protein expression levels and miR expression (particularly miR-141 and miR-1184) was identified. This indicates that these miRs may regulate the expression of PD-L1 at a post-transcriptional level, and thus participate in tumor-cell escape from immune surveillance. However, these miRs are not involved in mRNA degradation, which can be stored in the cell and activated if necessary. Positive correlations may indicate that these two miRs (which exhibit increased expression levels) may be able to silence PD-L1 expression in cancerous cells, but that this is restricted by the carcinogenetic characteristics of these cells, allowing them to bypass epigenetic regulation. This hypothesis evidently requires experimental confirmation, potentially with a larger patient cohort and in vitro experimentation using cell lines. Furthermore, no relevant publications on the subject were identified, thus extended studies including biochemical and molecular biological experiments will increase knowledge of the regulatory functions of miR-141 and miR-1184 in association with PD-L1. Due to the small size of the patient group, the present study may be considered as a pilot study to indicate subsequent genetic and epigenetic experimentation surrounding PD-L1 immunotherapy.
miRs are able to act as oncogenes or tumor suppressors, depending on the cancer type in question (27). There is limited evidence of miR-1184 expression in different types of cancer. Knyazev et al (28) demonstrated the potential of miR-1184 to differentiate between prostate cancer and benign prostatic hyperplasia, indicating higher levels of miR-1184 expression in the peripheral blood of patients with prostate cancer. Feng et al (29) revealed that miR-1184 was able to regulate the expression of certain oncogenes and transcription factors, including SMAD family member 5, signal transducer and activator of transcription 3 and glioma-associated oncogene family zinc finger 3. Farina et al (30) identified lower expression levels of miR-1184 in patients with breast cancer, compared with healthy controls.

Mei et al (31) demonstrated that miR-141 was upregulated in NSCLC, which was associated with aggressive disease course and accelerated tumor growth. It was indicated to regulate $\mathrm{PH}$ domain and leucine-rich repeat protein phosphatase 1 (PHLPP1) and PHLPP2, which are involved in the AKT serine/threonine kinase 1 pathway and oncogenesis. In turn, Zuo et al (32) identified miR-141 as a tumor suppressor in gastric cancer; it was concluded that decreased expression of this miR was correlated with a more aggressive phenotype, compared with the healthy controls. Further analysis demonstrated that miR-141 targeted transcriptional co-activator with PDZ-binding motif, a transcriptional coactivator that promotes cell proliferation and epithelial-mesenchymal transition. Furthermore, ectopic overexpression of miR-141 suppressed tumor growth and pulmonary metastasis in nude mice.

There is no clear evidence of the regulation of the immune response and PD-L1 expression by miRs. However, Huang et al (33) indicated that miR-141 targets C-X-C motif chemokine ligand 12 , and thus participates in the control of colonic leukocyte trafficking during Crohn's disease-associated intestinal inflammation.

Another molecule identified as a potential regulator of PD-L1 is miR-200b. A correlation between the expression levels of miR-200b and PD-L1 on tumor and immune cells was indicated. miR-200b belongs to the family which also includes miR-141, miR-200a, miR-429 and miR-200c, though its role in NSCLC development is not well understood. Xiao et al (34) postulated that the overexpression of this miR may inhibit NSCLC cell migration and invasion. It was indicated that miR-200b regulates fascin actin bundling protein 1 and therefore, is involved in the regulation of cell migration, motility, adhesion and other cellular interactions. Gibbons et al (35) stated that epithelial-mesenchymal transition (ETM) is entirely dependent on the expression of the miR-200 family, which decreased during EMT. A high miR-200 expression level inhibits tumor cell migration and metastasis.

In the present study, expression of another member of the miR-200 family, miR-429, was correlated with PD-L1 protein expression. Xiao et al (36) indicated that overexpression of miR-429 resulted in increased NSCLC cell proliferation, while knockdown of miR-429 attenuated the proliferation of H1229 cells. This was partially due to the regulation of tumor suppressor deleted in liver cancer 1 (DLC-1) expression by miR-429, suggesting that miR-429 may have an oncogenic role in the regulation of cell proliferation via the direct inhibition of DLC-1 protein expression in tumor cells. 
In the present study, a significant association between PD-L1 mRNA level and PD-L1 protein expression on tumor cells was also demonstrated. Erber et al scored PD-L1 mRNA and PD-L1 protein expression on tumor cells, where a notable association between the expression level of PD-L1 mRNA and protein was identified in NSCLC (37). This suggested that in patients with PD-L1 protein expression on $>50 \%$ of tumor cells, PD-L1 mRNA may be reliably detected by RT-qPCR, and that quantitative PD-L1 mRNA scoring may be considered as an alternative to IHC (37). On the other hand, Sepesi et al (38) suggested that the value of PD-L1 mRNA expression analysis in the diagnosis and prognosis of lung cancer is limited. It was demonstrated that PD-L1 mRNA expression in lung cancer was higher compared with in normal tissues and other tumor types. Furthermore, mRNA expression level was significantly higher in lung squamous cell carcinoma compared with adenocarcinoma. Other than PD-L1 mRNA, the authors suggested that further studies were required to identify novel prognostic biomarkers that are associated with improved patient survival and may be useful in identifying patients suitable for immunotherapy (38).

There is a requirement for further studies to assess the association between the expression of miR and PD-L1, as such interactions may partially explain the varied responses to immunotherapy between patients. In the present study, the positive correlation between the expression level of PD-L1 mRNA and the miR-200 family indicated no transcript degradation. The mechanism for regulation of PD-L1 expression on tumor cells remains unclear. However, miRs may serve an important role in this process, and the study of their expression may result in the discovery of novel predictors for immunotherapy.

\section{Acknowledgements}

Not applicable.

\section{Funding}

No funding was received.

\section{Availability of data and materials}

The datasets used and/or analyzed during the present study are available from the corresponding author on reasonable request.

\section{Authors' contributions}

AG, MN, MSz and PK contributed to conception and design of the study. JP, MSa, JS, PK and JM acquired the data, and MN, TK and BJ conducted the laboratory experiments. MN, AG, BJ, JP and PB analyzed and interpreted the data, and AG, PK and TK were involved in drafting the manuscript or revising it critically for important intellectual content. AG, MN, MSz, PK, BJ, JP, MSa JS, PB and JM gave final approval of the published manuscript.

\section{Ethics approval and consent to participate}

The present study was approved by the Ethics Committee of the Medical University of Lublin (Lublin, Poland) (no. KE-0254/169/2014). All participants provided written informed consent to participate.

\section{Patient consent for publication}

Not applicable.

\section{Competing interests}

The authors declare that they have no competing interests.

\section{Reference}

1. Muenst S, Soysal SD, Tzankov A and Hoeller S: The PD-1/PD-L1 pathway: biological background and clinical relevance of an emerging treatment target in immunotherapy. Expert Opin Ther Targets 19: 201-211,2015.

2. Sharma P and Allison JP: The future of immune checkpoint therapy. Science 348: 56-61, 2015.

3. Zou W, Wolchok JD and Chen L: PD-L1 (B7-H1) and PD-1 pathway blockade for cancer therapy: mechanisms, response biomarkers, and combinations. Sci Transl Med 8: 328rv4, 2016.

4. Weber JS, D'Angelo SP, Minor D, Hodi FS, Gutzmer R, Neyns B, Hoeller C, Khushalani NI, Miller WH Jr, Lao CD, et al: Nivolumab versus chemotherapy in patients with advanced melanoma who progressed after anti-CTLA-4 treatment (CheckMate 037): a randomised, controlled, open-label, phase 3 trial. Lancet Oncol 16: 375-384, 2015.

5. Horn L, Spigel DR, Vokes EE, Holgado E, Ready N, Steins M, Poddubskaya E, Borghaei H, Felip E, Paz-Ares L, et al: Nivolumab versus docetaxel in previously treated patients with advanced non-small-cell lung cancer: two-year outcomes from two randomized, open-Label, phase III trials (CheckMate 017 and CheckMate 057). J Clin Oncol 35: 3924-3933, 2017.

6. Reck M, Rodríguez-Abreu D, Robinson AG, Hui R, Csőszi T, Fülöp A, Gottfried M, Peled N, Tafreshi A, Cuffe S, et al; KEYNOTE-024 Investigators: pembrolizumab versus chemotherapy for PD-L1-positive non-small-cell lung cancer. N Engl J Med 375: 1823-1833, 2016.

7. Gandhi L, Rodríguez-Abreu D, Gadgeel S, Esteban E, Felip E, De Angelis F, Domine M, Clingan P, Hochmair MJ, Powell SF, et al; KEYNOTE-189 Investigators: pembrolizumab plus chemotherapy in metastatic non-small-cell lung cancer. N Engl J Med 378: 2078-2092, 2018.

8. Sharma P and Allison JP: Immune checkpoint targeting in cancer therapy: toward combination strategies with curative potential. Cell 161: 205-214, 2015.

9. Borghaei H, Paz-Ares L, Horn L, Spigel DR, Steins M, Ready NE, Chow LQ, Vokes EE, Felip E, Holgado E, et al: Nivolumab versus docetaxel in advanced nonsquamous non-small-cell lung cancer. N Engl J Med 373: 1627-1639, 2015.

10. Brahmer J, Reckamp KL, Baas P, Crinò L, Eberhardt WE, Poddubskaya E, Antonia S, Pluzanski A, Vokes EE, Holgado E, et al: Nivolumab versus docetaxel in advanced squamous-cell non-small-cell lung cancer. N Engl J Med 373: 123-135, 2015.

11. Garon EB, Rizvi NA, Hui R, Leighl N, Balmanoukian AS, Eder JP, Patnaik A, Aggarwal C, Gubens M, Horn L, et al; KEYNOTE-001 Investigators: pembrolizumab for the treatment of non-small-cell lung cancer. N Engl J Med 372: 2018-2028, 2015.

12. Gadgeel S, Kowanetz M, Zou W, Hirsch FR, Kerr KM, Gandara DR, Barlesi F, Park K, McCleland M, Koeppen H, et al: Clinical efficacy of atezolizumab (Atezo) in PD-L1 subgroups defined by SP142 and 22C3 IHC assays in 2L+NSCLC: results from the randomized OAK study. Ann Oncol 28 (Suppl 5): v460-v496, 2017.

13. Mino-Kenudson M: Immunohistochemistry for predictive biomarkers in non-small cell lung cancer. Transl Lung Cancer Res 6: 570-587, 2017.

14. Brogden KA, Parashar D, Hallier AR, Braun T, Qian F, Rizvi NA, Bossler AD, Milhem MM, Chan TA, Abbasi T and Vali S: Genomics of NSCLC patients both affirm PD-L1 expression and predict their clinical responses to anti-PD-1 immunotherapy. BMC Cancer 18: 225, 2018. 
15. Pillai RS: MicroRNA function: Multiple mechanisms for a tiny RNA? RNA 11: 1753-1761, 2005.

16. Parker R and Sheth U: P bodies and the control of mRNA translation and degradation. Mol Cell 25: 635-646, 2007.

17. Wang Q, Lin W, Tang X, Li S, Guo L, Lin Y and Kwok HF: The roles of microRNAs in regulating the expression of PD-1/PD-L1 immune checkpoint. Int J Mol Sci 18: E2540, 2017.

18. Xie WB, Liang LH, Wu KG, Wang LX, He X, Song C, Wang YQ and Li YH: MiR-140 expression regulates cell proliferation and targets PD-L1 in NSCLC. Cell Physiol Biochem 46: 654-663, 2018.

19. Gibbons DL, Chen L, Goswami S, Cortez MA, Ahn YH, Byers LA, Lin W, Diao L, Wang J, Roybal J, et al: Regulation of tumor cell PD-L1 expression by microRNA-200 and control of lung cancer metastasis. J Clin Oncol 32 (suppl 15): 8063-8063, 2015.

20. Schmittgen TD and Livak KJ: Analyzing real-time PCR data by the comparative C(T) method. Nat Protoc 3: 1101-1108, 2008.

21. Rudzki JD: Management of adverse events related to checkpoint inhibition therapy. Memo 11: 132-137, 2018.

22. Postow MA, Sidlow R and Hellmann MD: Immune-related adverse events associated with immune checkpoint blockade. N Engl J Med 378: 158-168, 2018.

23. Rittmeyer A, Barlesi F, Waterkamp D, Park K, Ciardiello F, von Pawel J, Gadgeel SM, Hida T, Kowalski DM, Dols MC, et al; OAK Study Group: Atezolizumab versus docetaxel in patients with previously treated non-small-cell lung cancer (OAK): A phase 3, open-label, multicentre randomised controlled trial. Lancet 389: 255-265, 2017.

24. Herbst RS, Soria JC, Kowanetz M, Fine GD, Hamid O, Gordon MS Sosman JA, McDermott DF, Powderly JD, Gettinger SN, et al: Predictive correlates of response to the anti-PD-L1 antibody MPDL3280A in cancer patients. Nature 515: 563-567, 2014.

25. Rizvi NA, Hellmann MD, Snyder A, Kvistborg P, Makarov V, Havel JJ, Lee W, Yuan J, Wong P, Ho TS, et al: Cancer immunology. Mutational landscape determines sensitivity to PD-1 blockade in non-small cell lung cancer. Science 348: 124-128, 2015.

26. Shukuya T, Amann J, Ghai V, Wang K and Carbone DP: Circulating miRNA and extracellular vesicle containing miRNA as response biomarkers of anti PD-1/PD-L1 therapy in non-small-cell lung cancer. J Clin Oncol 36 (Suppl 15): 3058: 2018.

27. Bracken CP, Gregory PA, Kolesnikoff N, Bert AG, Wang J, Shannon MF and Goodall GJ: A double-negative feedback loop between ZEB1-SIP1 and the microRNA-200 family regulates epithelial-mesenchymal transition. Cancer Res 68: 7846-7854, 2008 .
28. Knyazev EN, Fomicheva KA, Mikhailenko DS, Nyushko KM, Samatov TR, Alekseev BY and Shkurnikov MY: Plasma levels of hsa-miR-619-5p and hsa-miR-1184 differ in prostatic benign hyperplasia and cancer. Bull Exp Biol Med 161: 108-111, 2016.

29. Feng F, Wu J, Gao Z, Yu S and Cui Y: Screening the key microRNAs and transcription factors in prostate cancer based on microRNA functional synergistic relationships. Medicine (Baltimore) 96: e5679, 2017.

30. Farina NH, Ramsey JE, Cuke ME, Ahern TP, Shirley DJ, Stein JL, Stein GS, Lian JB and Wood ME: Development of a predictive miRNA signature for breast cancer risk among high-risk women. Oncotarget 8: 112170-112183, 2017.

31. Mei Z, He Y, Feng J, Shi J, Du Y, Qian L, Huang Q and Jie Z: MicroRNA-141 promotes the proliferation of non-small cell lung cancer cells by regulating expression of PHLPP1 and PHLPP2. FEBS Lett 588: 3055-3061, 2014.

32. Zuo QF, Zhang R, Li BS, Zhao YL, Zhuang Y, Yu T, Gong L, Li S, Xiao B and Zou QM: MicroRNA-141 inhibits tumor growth and metastasis in gastric cancer by directly targeting transcriptional co-activator with PDZ-binding motif, TAZ. Cell Death Dis 6: e1623, 2015.

33. Huang Z, Shi T, Zhou Q, Shi S, Zhao R, Shi H, Dong L, Zhang C, Zeng K, Chen J, et al: miR-141 Regulates colonic leukocytic trafficking by targeting CXCL12 $\beta$ during murine colitis and human Crohn's disease. Gut 63: 1247-1257, 2014

34. Xiao P, Liu W and Zhou H: miR-200b inhibits migration and invasion in non-small cell lung cancer cells via targeting FSCN1. Mol Med Rep 14: 1835-1840, 2016

35. Gibbons DL, Lin W, Creighton CJ, Rizvi ZH, Gregory PA, Goodall GJ, Thilaganathan N, Du L, Zhang Y, Pertsemlidis A, et al: Contextual extracellular cues promote tumor cell EMT and metastasis by regulating miR-200 family expression. Genes Dev 23: 2140-2151, 2009.

36. Xiao P, Liu W and Zhou H: miR-429 promotes the proliferation of non-small cell lung cancer cells via targeting DLC-1. Oncol Lett 12: 2163-2168, 2016.

37. Erber R, Stöhr R, Herlein S, Giedl C, Rieker RJ, Fuchs F, Ficker JH, Hartmann A, Veltrup E, Wirtz RM, et al: Comparison of PD-L1 mRNA expression measured with the CheckPoint Typer ${ }^{\circledR}$ Assay with PD-L1 protein expression assessed with immunohistochemistry in non-small cell lung cancer. Anticancer Res 37: 6771-6778, 2017.

38. Sepesi B, Nelson DB, Mitchell KG, Gibbons DL, Heymach JV, Vaporciyan AA, Swisher SG and Roszik J: Prognostic value of PD-L1 mRNA sequencing expression profile in non-small cell lung cancer. Ann Thorac Surg 105: 1621-1626, 2018. 